\title{
RECENT TRENDS IN THE BIOCHEMISTRY OF THË GROUND SUBSTANCE OF THE CONNECTIVE \\ TISSUES
}

\author{
A. G. Lloyd, B.Sc., Ph.D., A.R.I.C. \\ Senior Lecturer in Biochemistry and Member of the M.R.C. Research Group for Studies on Connective $\overparen{\mathbb{D}}$ \\ Tissue and Lung, University College, Cardiff.
}

THE UBIQUITY of members of the anatomical group loosely defined as connective tissues is a matter of long-standing record. The same comment applies to the convention that, despite the differing biological roles which they are required to play and their characteristically different mechanical character at macroscopic level, the individual members of the connective tissue group exhibit certain basic similarities which first become apparent at microscopic level. A common biochemical approach is to develop these features of similarity to a point where an idealised composite of all connective tissues can be devised. Use of such a model allows initial broad generalisations to be drawn. On the other hand, the same model must subsequently be employed to establish not only morphological but fundamental biochemical differences which exist between the tissues.

A model connective tissue is usually conceived as containing relatively few cells per unit volume compared to a highly cellular organization such as liver and additionally differentiated from the latter by the presence of a significant quantity of extracellular material. This material is characterised by the presence of organised fibrillar elements, composed variously of the biochemically distinct proteins collagen, elastin and reticulin, these being embedded in an amorphous medium termed the ground substance.

In this context, it is fitting that laboratories in the Cardiff area should be connected in studies on all aspects of pulmonary dust disease and in particular of coal miner's pneumoconiosis, progressive massive fibrosis and silicosis. The need for such work is presented with considerable impact in the observations of Gough (1947). Much has already been established about the statistical incidence and pathological characteristics of such dust diseases, but their true ætiology is still a matter for conjecture (Policard, 1962). However, from the simplified histological standpoint the human lung lesion in such conditions shows characteristically an increased 'fibrosis' when compared to the surrounding tissue, the fibres usuafly being described as collagenous. As yet there is no clear indication whether such fibrosess arise according to the partially establisheel pattern of inflammatory response in which the earliest recognisable biochemical changes i.7.clude alterations in the ground substance of connective tissues followed only subsequently by de novo formation of additional fibrous material. It is for this reason that the researes group housed in the Department of Biochemis:try is designed to assist in the clarification of fundamental biochemical changes associated with general lung dust diseases from the aspert of disturbed connective tissue metabolism. Such an approach must obviously take into accoug the many recent developments concerningothe nature and properties of the structural elements of the connective tissues and in particular intrinsic complexity of the ground substance.

\section{The Ground Substance}

There is now no doubt that histologicall examination of connective tissues using copventional techniques provides a wholly incornplete and frequently artificial picture of the complexity of the ground substance. It has even been established that long-used methods of tissue fixation may even facilitate the extraz. tion of ground substance constituents (see Szirmai, 1963). Thus, even for relatively grosss histological observations such methods must be replaced by the use of modified tissue fixa tives (Quintarelli, Scott and Dellovo, 1964a) or alternatively frozen section techniques ip which 'fixation' is virtually carried out in the dye bath (Szirmai, 1963). Methods have be come available for differentiating some of the ground substance components by selectice physico-chemical blocking and unblocking 审 the presence of quaternary ammonium conpounds (Kelly, Bloom and Scott, 1963), by selective staining in the presence of solutions of varying $\mathrm{pH}$ or electrolyte concentratich (Szirmai, 1963; Saunders, 1964; Quintarelf, 
Scott and Dellovo, 1964b) and by selective enzymic digestion (Zugibe, $1962 \mathrm{a}$ and b). However, such techniques continue to be the province of the specialist in the field, rather than methods of routine applicability. As such, much reliance must still be placed on approaches based on the extraction of connective tissue components followed by their characterisation using physical, chemical and biochemical methods. Even in this regard studies initiated during the middle of the last century and subsequently prosecuted with increasing vigour are still the subject of continuous contemporary reappraisal.

\section{Polysaccharide-Protein Complexes of the Ground Substance}

\section{The Polysaccharides}

Early studies on these materials invariably involved treatment of connective tissues under relatively vigorous conditions such as prolonged digestion with proteolytic enzymes followed by extraction with strong salt solutions or even dilute alkali. The resultant extracts yielded, by several methods of purification, varying amounts of one or more of a group of carbohydrate high polymers. These have been variously and synonymously termed acid mucopolysaccharides, acid aminopolysaccharides or more recently acid glycosaminoglycans (Jeanloz, 1960). In defining the purity of such materials early workers attached much significance to the absence of amino acid and polypeptide residues from the polysaccharide preparations and when demonstrated such 'contamination' was frequently attributed to inefficiency of purification procedures. Structural studies (reviewed by Jeanloz, 1963) on these compounds reveal a pattern of similar molecular organization. Thus, in the main they are relatively high molecular weight polysaccharides having linear chains containing hexosamine residues. The latter may be either D-glucosamine or D-galactosamine each occurring in a state in which the amine grouping is blocked. The hexosamines alternate regularly in the polymer chains with other monosaccharide residues which may be hexuronic acids, such as $D$ glucuronic acid and L-iduronic acid or a hexose such as D-galactose.

All of the polysaccharides are also polyanions, the negative charge arising either from the carboxyl group of the above uronic acids or from the presence of ester bound sulphate, or both. Accepted structures show the potentially charged groups arranged regularly along the polymer chains. As both carboxyl and sulphate groups are fully ionized at physiological $\mathrm{pH}$ the resultant highly negative character is likely to have considerable bearing on the functions attributed to the polymers in the native state.

The acidic glycosaminoglycans recognised to date fall into four classes, differentiated by features of chemical fine structure:

A. Polysaccharides having anionic character conferred solely by hexuronic acid constituents e.g., hyaluronic acid and chondroitin.

B. Polysaccharides having anionic character resulting from the dual presence of hexuronic acid and O-sulphate groups e.g., chondroitin 4-sulphate (syn. chondroitin sulphate-A), chondroitin 6-sulphate (syn. chondroitin sulphate-C) and dermatan sulphate (syn. chondroitin sulphate- $B, \beta$-heparin).

C. Polysaccharides having $O$-sulphate groups as sole functional anionic entities e.g., keratan sulphate (syn. keratosulphate).

D. Polysaccharides characterised by the presence of hexuronic acid, $\mathrm{O}$-sulphate and $\mathrm{N}$ sulphate residues e.g., heparan sulphates (syn. heparitin sulphates). Heparin and $\omega$-heparing may also be included in this class for the sake of completeness.

The compositions of each of these materials is shown in Table 1 and the major repeating periods of the polysaccharides from Classes A, $\mathrm{B}$ and $\mathrm{C}$ are summarised in Figs. 1,2 and 3 respectively. These should be considered to be structures derived on the principle of best analytical evidence. While there is little doubt that they account for the format of the major portion of the polysaccharide chains there are indications that some regions of the polymers are not constructed in this way. Such evidence will be dealt with later. It should also be noted that variability of sulphate analysis is not an uncommon occurrence and that acid glycosaminoglycan preparations with sulphur to nitrogen ratios both greater and less than unity have been isolated. Conclusive data allowing the assignment of wholly acceptable repeating period structures for heparan sulphates (and for heparin and $\omega$-heparin) has yet to be obtained (see Muir, 1964).

Aside from the significant contributions which they have made in structural work on the acid glycosaminoglycans, elegant studies made by Professor Karl Meyer and his colleagues lay a foundation for the concept that connective tissues fulfilling distinctive biological functions are also provided with differing 
TABLE 1

Major CONSTituents of THE Acidic Glycosaminoglycans

Polysaccharides

\section{CLASS A}

Hyaluronic Acid

Chondroitin

CLASS B

Chondroitin 4-Sulphate

Chondroitin 6-Sulphate

Dermatan Sulphate

CLASS C

Keratan Sulphate

CLASS D

Heparan Sulphates

Heparin
Hexosamine

D-Glucosamine

D-Galactosamine

D-Galactosamine

D-Galactosamine

D-Galactosamine

D-Glucosamine

D-Glucosamine

D-Glucosamine

\section{Other} Monosaccharide

N-Acetyl Group

\section{O-Sulphate}

Group (s)
D-Glucuronic Acid

D-Glucuronic Acid

D-Glucuronic Acid

D-Glucuronic Acid

L-Iduronic Acid

D-Galactose

D-Glucuronic Acid

D-Glucuronic Acid

N-Sulphatẹ

Group $\stackrel{\Rightarrow}{\Rightarrow}$

$\begin{array}{ll}+ & - \\ + & - \\ + & + \\ + & + \\ + & + \\ + & + \\ + & + \\ - & +\end{array}$

(a)

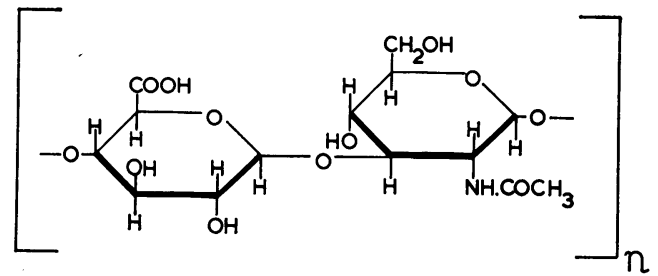

(b)

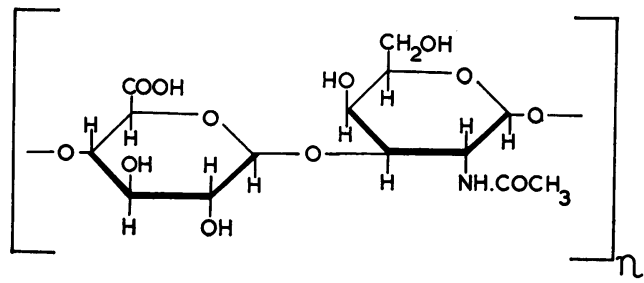

FIG. 1.-Structures of the repeating periods in hyaluronic acid (a) and chondroitin (b).

complements of the acidic polysaccharides (Meyer, Davidson, Linker and Hoffman, 1956). Table 2 is a summary of part of the original work plus some additional information, giving analyses for tissues of average chronological age. On the other hand, it should also be stressed that the content of acid glycosaminoglycans must not be considered to be static throughout life. Thus, apart from variations due to metabolic turnover, changes both in overall content and in the concentration ratios of individual polysaccharides as a function of age have also been observed. For example, embryonic pig skin polysaccharides are comprised of $9.5 \%$ dermatan sulphate, $71 \%$ hyaluronic acid and about $20 \%$ of a mixture of chondroitin 4-sulphate and chondroitin 6-sulphate. Analyses of adult pigskin reveals a sharp change in ratio corresponding to $64 \%$
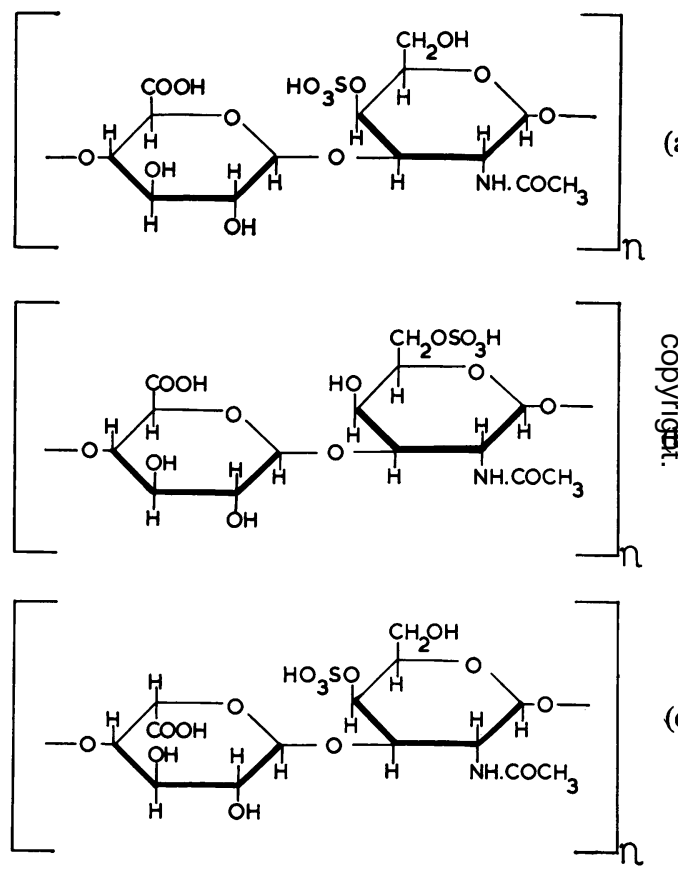

FIG. 2.-Structures of the repeating periods in choro droitin 4-sulphate (a), chondroitin 6-sulphate (b) and dermatan sulphate (c).

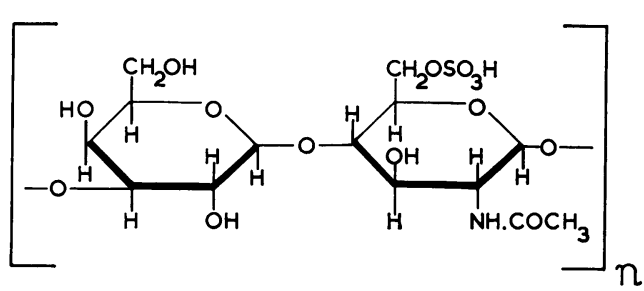

FIG. 3.-Structure of the repeating period in kerata sulphate. 
TABLE 2

Distribution of Acidic Glycosaminoglycans in Mammalian Connective Tissue POLYSACCHARIDES

\begin{tabular}{|c|c|c|c|c|c|c|c|c|}
\hline Tissues & $\begin{array}{l}\text { Hyaluronic } \\
\text { Acid }\end{array}$ & Chondroitin & $\begin{array}{c}\text { Chondroitin } \\
\text { 4-Sulphate }\end{array}$ & $\begin{array}{l}\text { Chondroitin } \\
\text { 6-Sulphate }\end{array}$ & $\begin{array}{l}\text { Dermatan } \\
\text { Sulphate }\end{array}$ & $\begin{array}{r}\text { Keratan } \\
\text { Sulphate }\end{array}$ & $\begin{array}{l}\text { Heparan } \\
\text { Sulphate }\end{array}$ & Heparin \\
\hline Synovial Fluid & + & - & - & - & - & - & - & - \\
\hline Cartilage & - & - & + & + & - & + & - & - \\
\hline Bone & - & - & + & + & - & + & - & - \\
\hline Tendon & + & - & - & + & + & - & - & - \\
\hline Ligamentum Nuchae & + & - & + & - & + & + & - & - \\
\hline Skin & + & - & \pm & \pm & + & - & + & + \\
\hline Aorta & + & - & + & - & + & - & + & + \\
\hline $\begin{array}{l}\text { Vitreous Humor } \\
\text { Cornea }\end{array}$ & + & $\bar{t}$ & 二 & - & - & - & - & - \\
\hline $\begin{array}{l}\text { Cornea } \\
\text { Sclera }\end{array}$ & 二 & \pm & + & F & \pm & + & - & - \\
\hline Umbilical Cord & + & - & - & - & I & 二 & - & - \\
\hline
\end{tabular}

dermatan sulphate, $30 \%$ hyaluronic acid and some $0.1 \%$ of the chondroitin 4-sulphatechondroitin 6-sulphate mixture (Loewi and Meyer, 1958). Similar effects have been observed in rat and in man (Loewi, 1961; Prodi, 1964). In addition Kaplan and Meyer (1959) recorded that in human costal cartilage there is a decrease in the overall content of acidic glycosaminoglycans with age. The same authors have shown that in phase with this decrease the constituent polysaccharides change from exclusively chondroitin 4-sulphate in foetal costal cartilage to a mixture of chondroitin 6sulphate and keratan sulphate in cartilage from the same location in adults. These selected examples can be considered to be representative of phenomena which are likely to become the rule for all connective tissues rather than exceptional observations.

The distributions summarized in Table 2 are based on analyses of 'bulk' samples of material where the morphological integrity of the tissue is destroyed at an early stage of the extraction procedure and therefore correspond to average results for fairly large volumes of tissue. As such they give no indication whether the polysaccharides are arranged homogeneously throughout the whole ground substance or whether in fact they are the subject of concentration and localisation effects in relation to the fine structure of the tissue. Such information is clearly of prime importance to assessments of the functional significance of individual acid glycosaminoglycans. Antonopoulos, Gardell, Szirmai and de Tyssonsk (1964) have recognised the need for means to carry out precise surveys. These authors are responsible for the development of methods which allow alternate tissue sections $(10-40 \mu$ thick) to be examined qualitatively by histological means and quantitatively by micro-scale modifications of established chemical methods. Data collected in this way allows the construction of concentra- 3 .

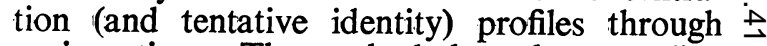
a given tissue. The methods have been applied to studies on bovine nasal septum and rabbit intervertebral disc (Antonopoulos and others, $1964)$ and to epiphyseal plates from normal and rachitic dogs (Hjertquist, 1964a, b). The resulting observations establish that the acid glycosaminoglycans are subject not only to gross variation from tissue to tissue and to age fluctuations in the same tissue but also to three dimensional variations in a given tissue of defined age.

\section{The Complexes}

The 'pure' polysaccharides required for structural studies do not exist as such at tissue level and are, in a sense, chemical artifacts produced by the relatively vigorous means used for extraction. Application of milder methods, such as physical disintegration of the tissue by high speed homogenisation, yields the acid glycosaminoglycans linked firmly to protein moieties by covalent bonds (see for example Shatton and Schubert, 1954; Gerber, Franklin and Schubert, 1960). Erroneous implications should not be drawn from the persistent use of the generic nomenclature of polysaccharide-protein complexes for these materials when obviously the term compound would be far more appropriate.

In recent years the most extensively studied complex is that derived from various kinds of cartilage. Preliminary work conceived the cartilage chondromucoprotein complex as consisting of numerous polysaccharide chains (largely chondroitin 4-sulphate or 6-sulphate plus some keratan sulphate) firmly attached to a median, non-collagenous protein core (Partridge, Davis and Adair, 1961). It is a characteristic of the cartilage complexes that 
the polysaccharide moieties are cleaved irreversibly from the protein chain by treatment with dilute alkali (Muir, 1958; Partridge and Davis, 1958; Malawista and Schubert, 1958; Partridge and Elsden, 1961). However, the work of Muir (1958) established that when the isolated complex from cartilage was exhaustively degraded with proteolytic enzymes in vitro the polysaccharide preparations subsequently isolated were still firmly associated with serine-rich polypeptide stubs. Such observations focussed considerable attention on the possibility that serine residues in the original core material were intimately concerned in the linkage of polysaccharide and protein. The value of this initial work is illustrated by the recent isolation from a chondroitin sulphate-protein complex of carbohydrate residues linked directly to serine (Rodén, Gregory and Laurent, 1964). Evidence has been presented (Dr. L. Rodén, personal communication) that a novel carbohydrate linkage sequence, comprising xylose and galactose moieties, is involved as a bridge between the serine hydroxyl and the characteristic repeating periods of the glycosaminoglycan chain. These observations are by no means unique to the chondroitin sulphate-protein complexes as similar linkage arrangements are also found in heparin-polypeptide complexes (Lindahl and Rodén, 1964). Heparan sulphateprotein complexes are likely to be bonded in an analogous fashion (Jacobs and Muir, 1964).

Treatment of glycosaminoglycan-protein complexes with alkali and analysis of the products of reaction provides a relatively rapid means for assessing the participation of serine and threonine in glycoprotein linkage (Anderson, Seno, Sampson, Riley, Hoffman and Meyer, 1964; Anderson, Hoffman and Meyer, 1965). Studies using these alkaline degradation methods reveal the involvement of hydroxylated alkyl amino acid residues in linkages between protein and chondroitin 4-sulphate, chondroitin 6-sulphate and skeletal keratan sulphate. However, bonds in the corresponding complexes of chondroitin, dermatan sulphate and corneal keratan sulphate are suggested to be of the asparaginyl-glycosyl type as found in $a_{1}$-glycoprotein (Professor K. Meyer, personal communication).

There is no clear indication whether a single type of acid glycosaminoglycan may be attached to protein cores of different amino acid constitution. However, it has been shown that bovine nasal septum cartilage yields two varieties of chondroitin sulphate-protein complex, distinguished by their differential sedimen- tation in the ultracentrifuge (Gerber, FrankFin and Schubert, 1960). The large particle fracktion (designated $\mathrm{PP}-\mathrm{H}$ ) has a substantiafty higher protein content than the lighter (socalled PP-L) fraction. Both PP-H and PP also contain small amounts of materials cognisable as keratan sulphate and sialic aci Differences have been noted in the PP-H: PPज्ञ ratio in cartilages from varying anatomical log tions. Thus, human costal cartilage, in contrast to bovine nasal septum, contains a large proportion of PP-H and a correspondingly smaller amount of PP-L, both fractions having $\overrightarrow{\mathrm{c}^{a}}$ higher content of keratan sulphate and proportionately less chondroitin sulphate. Furthe more, human costal cartilage PP-L shows two distinot components on electrophorestis (Schubert, 1964). No information is yet avaitable regarding a similar pattern of behaviour for the protein complexes of other acgit glycosaminoglycans.

Lastly, it is necessary to record that hyaluronic acid exists naturally in firm combination with protein (Rogers, 1961). Even in thiss instance complicating features have arisen since it has been suggested that up to $10 \%$ of the hyaluronic acid molecule may not $\mathrm{Be}$ constructed according to the accepted repeatify period plan (Montgomery and Nag, 1963)

The examples given are designed to show the new approaches which are being made th studies on the chemical constitution of the ground substance. However, they also serge to illustrate the complexity of the situation which exists in a highly vascular organ sued as lung where biochemical events take place simultaneously at the interfaces of several distinct types of connective tissue.

The Biological Significance of the Complexes

It is now known that the biosynthesis of the complexes takes place inside the appropriate connective tissue cells. For example, studies with inorganic $\left[{ }^{35} \mathrm{~S}\right]$-sulphate and $\left[{ }^{14} \mathrm{C}\right]$-labelled amino acids reveal the concentration of the radioisotopes predominantly in the chondro cytes of bovine costal cartilage slices in vitrg (Campo and Dziewiatkowski, 1962). The same studies point to the simultaneous formation of the polysaccharide and the protein moieties of the chondroitin sulphate-protein comples However, it is still not clear at what stage the synthesis union between polysaccharide and protein is achieved. Godman and Lane (1964) have shown the localisation of $\left[{ }^{35} \mathrm{~S}\right]$-sulphat visualised autoradiographically, in vesicles of the juxtanuclear Golgi apparatus of chondro 
cytes, suggesting that the sulphation of the carbohydrate moieties at least occurs in this region of the cell. Subsequently, it is believed that the molecules of the intact complex are conveyed through the cytoplasm to the periphery of the cell in vesicle-like structures and then discharged into the extracellular matrix via stomata in the cell membrane (Godman and Porter, 1960; Sheldon and Robinson, 1960; Godman and Lane, 1964).

Once in the extracellular environment there is no doubt, for the chondromucoprotein complex of cartilage at least, that the biological stability and consequent functional significance of the polysaccharide chains is directly dependent on the integrity of the protein core. The remarkable finding that intravenous injection in young animals of the proteolytic enzyme papain produces the now renowned 'flop-ear' rabbits (see Thomas, 1956) may be explained it terms of in situ degradation of the protein core of the ear cartilage complex. In addition to the effect on ear cartilage the simultaneous and more widespread action of the enzyme throughout the body is illustrated by the disappearance of the matrix in all forms of cartilage as evidence by basophilic and metachromatic staining reactions. Similar experiments show the disappearance of extractable chondroitin sulphate from these tissues (Tsaltas, 1958) and its appearance in blood and urine (Bryant, Leder and Stetten, 1958). Papain introduced in this way shows greatest activity in young animals and towards cartilage, older animals becoming progressively more resistant presumably in phase with changes in the constitution of the ground substance. It is now known that such findings are not restricted to the injection of papain but also accompany the administration of ficin and bromelin (McCluskey and Thomas, 1958), while chondroitin sulphate is also liberated from cantilage by the action of plasmin (Lack and Rogers, 1958; Anderson, 1962). An endogenous protease, liberated in vivo or in vitro from mammalian lysozomes by the action of vitamin A etc. and its action on chondroitin sulphate-protein complexes, has been the subject of extensive examination (see Dingle, 1964, for the most recent review). To date attention has been devoted almost exclusively to studies on the degradation of cartilage protein-polysaccharide complexes and in consequence there is no appropriate information regarding the biological stabilities of the other materials.

In terms of percentage dry weight the protein complexes of the acidic polysaccharides appear to represent in many instances only an insignificant part of the ground substance of the connective tissues. However, considered as centres of intense anionic character there can be little doubt that in the tissues they are likely to exist as a focus for the concentration of inorganic cations. They must also participate in electrostatic interactions with proteins exhibiting cationic properties at physiological $\mathrm{pH}$. Obviously, highly ionic arrangements of this sort can only exist at tissue level in a state solvated with water molecules. The concept of 'dry weight' thus has little bearing on the physical existence of the complexes in the biological environment. It is conceived (see Schubert, 1964) that the complexes occur naturally as diffuse, extended macromolecular structures, each occupying an aqueous 'domain' that is large in comparison to the absolute weight of the complex. The interaction of each domain is envisaged as producing a three dimensional network, the pore size of which must obviously be governed by the degree of solvation, the intensity of charge and the chemical and physical fine structure of each complex. Experimental evidence suggests thato apart from a differential ability to bind cations according to the nature of the constituent glycosaminoglycans (Dunstone, 1960, 1962; Mathews, 1964) such three-dimensional molecular organizations should also be able to entangle particles (Laurent, 1964) and exclude large solutes (Gerber and Schubert, 1964). Viewed in this way it is tempting to suggest that the apparently precise biological allocation of structurally different anionic polysaccharideprotein complexes is a direct function of their variable properties in controlling ion-binding, water content and even the porosity of the tissue as a whole.

Opinions vary as to the extent to which the acidic glycosaminoglycans and their protein complexes participate in collagen fibrogenesis, both in the normal tissue and during the course of an inflammatory response. In some instances it has been suggested that because of their highly regular repeating character the polysaccharides may function intimately as templates or organizers in determining the size and geometrical arrangement of collagen fibres in the connective tissues (Meyer, 1960). Studies designed to explore the effect of chemically-pure acidic polysaccharides on the formation of collagen fibres in vitro tend to contradict this view. Gross (1959) found that a number of acidic glycosaminoglycans were 
without measurable effect on the rate of collagen fibril formation. The observations of Wood (1960) were partially at variance with the earlier findings in so far as chondroitin 4sulphate, chondroitin 6-sulphate and a preparation rich in keratan sulphate accelerated fibril formation markedly. Dermatan sulphate and hyaluronic acid had relatively little effect, while heparin actually inhibited precipitation. It is now obviously essential to repeat such in vitro studies on collagen fibre formation as a function of the presence of the intact polysaccharide-protein complexes and not merely the polysaccharides themselves. In the meanwhile it must be considered tentatively that the complexes are concerned with fibre binding and the limitation of collagen mobility in the three dimensional net of the ground substance.

\section{Acid Glycosaminoglycans in the Inflammatory Response.}

The last two decades have seen an expanding interest in the biochemical events involved in the processes of inflammation and wound repair. Perhaps the most astonishing feature of the ensuing work is the diversity of techniques and materials used in the induction of the inflammatory focus. Broadly speaking these fall under four major headings.

a. Wounding. Included in this section are observations on various cutaneous incisions and burns induced in mouse, rat, guinea pig, rabbit and man, together with studies on regenerating tendon in rat and guinea pig and bone fractures in various experimental animals.

b. Injection or implantation of 'resorbable' substances. The most widely examined responses here are granulomata induced subcutaneously, intraperitoneally and even in the cornea of several species of experimental animal by the introduction of agar, carrageenin, alginic acid, croton oil, oil of turpentine etc.

c. Injection or implantation of "non-resorbable substances'. Materials used in such experiments have included sections of polyvinyl sponge, cotton pellets, perforated stainless steel cylinders, mineral particles including talc, silica, coal and asbestos these being located in subcutaneous, intraperitoneal and pleural regions of various animals.

d. Lesions induced topically by irritation or other means. Examples here include skin irritation produced by various hydrocarbon oils and exposure to high frequency current or ionizing radiations.

It is surprising to note that the biochemical changes associated with connective tissue com- ponents apparent in each of these instance्s follows an almost identical broad sequen irrespective of the species of animal employed, differences in anatomical location and variations in the causative agent. Observed deviation from the sequence are almost invariably $\vec{\oplus} f$ degree rather kind.

Where measured it has been found that the earliest detectable biochemical event involves ${ }_{0}$ sharp, time-based increase in the nucleic agd (both DNA and RNA) content of the tissue in the vicinity of the inflammatory focus evidencing considerably elevated cellutajr activity. Such observations have been attributed both to the invasion of the area by cells amd to increased cell division.

Within a very short period after injury histochemical observations also show pronounced changes associated with the acid glycosamindglycans of the ground substance. Bogh metachromatic and colloidal iron staining actions are considerably intensified, a maximum usually being reached in 72-96 hours. Thereafter, there is a gradual decline in the intensiey of stain in healing wounds and in areas gf resorbing granulomata but a persistence in surrounding non-resorbable material.

The results of microscopic examinationfofe substantiated by biochemical studies. "I I variably the latter have involved analyses made for total hexosamine as a measure of overail glycosaminoglycan content, or for the individuail hexosamines D-glucosamine and D-galactosamine as an index of the presence of the corresponding parent polysaccharides. Alte natively, the magnitude of the uptake of inorganic [ ${ }^{35} \mathrm{~S}$ ] sulphate has been used as on indication of altered synthesis of sulphated glycosaminoglycans. The amounts of total hexosamine and $\left[{ }^{35} \mathrm{~S}\right]$ sulphate in inflamed aregs have been shown to increase abruptly, in some instances in parallel with the content of DNA and usually within 24 hours after injury. Maxima are reached in both series of deteminations in a matter of days, and may persist at these levels even after the nucleic acpel content has declined to 'normal' values. The rate of decline of hexosamine and $\left[{ }^{35} \mathrm{~S}\right]$ sulphate values, like the staining reactions, is a function of the material or technique used to produce the lesion and a persistence at levels aboge 'normal' is noted in areas surrounding nomresorbable material. Usually, in healing wounds and resorbable granulomata a return of hexosamine level to average values for the tissue is recorded by the time active formation 
of collagen fibres is already under way. In some instances the actual nature of the acidic glycosaminoglycans responsible for these analytical changes has been examined but the polymers produced and their ratios one to another are not unexpectedly varied according to the site of injury. However, as a general rule non-sulphated polymers such as hyaluronic acid tend to appear before the sulphated polysaccharides. No observations have yet been made concerning the protein moieties associated with the polysaccharides. In this regard it has been shown that the acid glycosaminoglycans of inflamed areas tend to become progressively more resistant with time to extraction with neutral salt solutions.

The significance of such changes in the ground substance in relation to fibrogenesis remains unclear, but may be considered tentatively as preparing the extracellular environment for the appearance of newly formed collagen. (Because of the large number of publications in this field individual references have been excluded to ensure continuity).

\section{Studies on Normal and Diseased Lung}

There are few recorded attempts to apply such methods to the study of normal lung and to pulmonary dust diseases in experimental animals and man. The interpretation of the results of such studies is also likely to be a complex matter. The connective tissues of the average normal lung are considered to contain dermatan sulphate, heparan sulphates and heparin (see Muir, 1964), each presumably stabilised as its protein complex. The presence of the chondroitin sulphates and keratan sulphate has also been detected in the vicinity of major airways, the content of the polymers increasing in progressive massive fibrosis in man (A. G. Lloyd, unpublished results). Constitutional studies will also have to take into account the various mucous secretions (Jakowska, 1963).

Studies on age-related changes in the connective tissues of lung have been directed largely to observations on the fibrous elements. Thus, it is now accepted generally that the proportion of lung 'collagen', measured in terms of hydroxyproline analyses per unit weight, increases in age in mice, rats, guinea pigs and humans (Elster and Lowry, 1950; Slutskii and Sheleketina, 1959; Briscoe, Loring Chvapil, 1957, 1960; Chvapil and Roth, 1964; and McClement, 1959; Boucek, Noble and Marks, 1961). However, there is also tentative evidence for the doubling of the elastin content of human lungs between the ages of 25 and 75 with no alteration in collagen content (Pierce, 1962).

Variation in the polysaccharide constitution of lung in experimental animals and man has been studied only through the medium of hexosamine analysis. Thus, Saltzman, Schauble and Siecker (1961) record little change with age of overall hexosamine content and in the ratio of galactosamine and glucosamine in lung parenchyma in rabbit and man. The same authors indicate statistically significant alteration of these values in lung parenchyma in certain cases of chronic disease. In contrast to such regions Saltzman, Siecker and Green (1963) indicate that there are significant age related decreases in bronchial cartilage hexosamine content and the galactosamine: glucosamine ratio in the absence of lung disease. It is interesting to compare these results with analogous age-related effects in rib cartilage and nucleus pulposus (Shetlar and Masters, 1955; Stidworthy, Masters and Shetlar, 1958; Kaplan and Meyer, 1959; Davidson and Woodhall, 1959). On the other hand, bronchial cartilage from emphysematous lung maintains a persistently higher ratio of galactosamine to glucosamine with advancing age in contrast to the progressive decrease observed with sene scence in specimens derived from normal lung

In relation to pulmonary dust disease Harington, Marasas, Melamed, Sutton and Dreosti (1960) were unable to show appreciable increase in total hexosamine content of guineapig lung after dusting for periods up to 70 days. However, these observations should be considered simultaneously with the report of Baily, Kilroe-Smith and Harington (1964) which shows a substantial increase in lung weight in dusted guinea pigs, the increase being due largely to materials low in hydroxyproline content. Lastly note should also be taken of observations of excessive production of hyaluronic acid in pleural mesotheliomas (Wagner, Munday and Harington, 1962).

\section{Conclusions}

It must be clear from the foregoing that much remains to be elucidated regarding the nature and properties of connective tissues, both in the normal lung and during pulmonary dust diseases. Furthermore, such v'ork must continue to proceed hand in hand with advances in general biochemical knowledge in relating to the connective tissue field as a whole, due regard always being given to studies on the mucous secretions of the respiratory tract. 


\section{REFERENCES}

ANDERSON, A. J. (1962): Some Studies on the Relationship between Sialic Acid and the Mucopolysaccharide-Protein Complexes in Human Cartilage, Biochem. J., 82, 372.

Anderson, B., Seno, N., SAmpson, P., Riley, J. G., HoffMAN, P. and MeYeR, K. (1964): Threonine and Serine Linkages in Mucopolysaccharides and Glycoproteins, J. biol. Chem., 239, 2716.

, Hoffman, $\dot{P}_{\text {., }}$ and MeYer, $\mathbf{K}$. (1965): The O-Serine Linkages in Peptides of Chondroitin 4- or 6-Sulfate, J. biol. Chem., 240, 156.

Antonopoulos, C. A., Gardell, S., Szirmai, J. A., and DE TYSSONSK, E. R. (1964): Determination of Glycosaminoglycans (Mucopolysaccharides) from Tissues on the Microgram Scale, Biochim. biophys. Acta. (Amst.), 83, 1.

Bailey, P., Kilroe-Smith, T. A., and Harington, J. S. (1964): Biochemistry of Lungs in Relation to Silicosis II. The Effect of Quartz Dust on the Protein Amino Acids of Guinea Pig Lung Tissue, Arch. environm. Hlth., 8, 547.

Bryant, J. H., LeDER, I. G. and StetTen, D. W. (1958): The Release of Chondroitin Sulphate from Rabbit Cartilage following the Intravenous Injection of Crude Papain, Arch. Biochem., 76, 122.

BrisCOE, A. M., LORING, W. E., and MCClemeNT, J. H. (1959): Changes in Human Lung Collagen and Lipids with Age, Proc. Soc. exp. Biol. Med., 102, 71 .

Boucek, R. J., Noble, N. L., and Marks, A. (1961): Age and the Fibrous Proteins of the Human Lung, Gerontologia (Basel), 5, 150.

CAMPO, R. D., and DZIEWIATKOWSKI, D. D. (1962): Intracellular Synthesis of Protein-Polysaccharide by Slices of Bovine Costal Cartilage, J. biol. Chem., 237, 2729.

ChVAPIL, M. (1957): Studies in Fibroplasia IV. Scleroproteins in the Lungs, Liver, Kidneys and Myocardium during Ontogeny in Rats, Physiol. Bohemoslov., 6, 102.

, (1960): Possibilities of Quantitative Determination of the Degree of Fibrosis in the Study of Experimental Silicosis, Beitr. Silikose-Forsch., 64, 1.

- and ROTH, Z. (1964): Connective Tissue Changes in Wild and Domesticated Rats, J. Gerontol., 19, 414.

Davidson, E. A., and Woodhall, B. (1959): Biochemical Alterations in Herniated Intervertebral Discs, J. biol. Chem. 234, 1959.

Dingle, J. T. (1964): Synthesis and Degradation of Connective Tissue in Organ Culture, in Proc. N.A.T.O. Advanced Study Institute on 'The Structure and Function of Connective and Skeletal Tissues', to be published.

DUNSTONE, J. R. (1960): Ion-Exchange Reactions Between Cartilage and Various Cations, Biochem. J., 77, 164.

DUNSTONE, J. R. (1962): Ion-Exchange Reactions Between Acid Mucopolysaccharides and Various Cations. Biochem. J., 85, 336.

ELSTER, G. K., and LOWRY, E. L. (1950): Collagen Content of Guinea Pig Tissue, Proc. Soc. exp. Biol. Med., 75, 127.

GERBER, B. R., and SChubERT, M. (1964): The Exclusion of Large Solutes by Cartilage Proteinpolysaccharide, Biopolymers, 2, 259.

- Frankin, E. C., and SCHUBERT, M. (1960): Ultracentrifugal Fractionation of Bovine Nasal Chondromucoprotein, J. biol. Chem., 235, 2870.
Godman, G. C., and Lane, N. (1964): On the Sife of Sulfation in the Chondrocyte, J. cell. Biol., 21, 253.

, and PORTER, K. R. (1960): Chondrogenests Studied with the Electron Microscope, J. Biophys. Biochem. Cytol., 8, 719.

Gough, J. (1947): Pneumoconiosis in Coal Workerts in Wales, Occup. Med., 4, 86.

Gross, J. (1959): On the Significance of the Solube Collagens in 'Connective Tissue, Thrombosis an Atherosclerosis', p. 77. New York: AcademPc Press.

Harington, J. S., Marasas, L. W., Melamed, M. Iீ SutTon, D. A., and Dreosti, I. (1960): Mucopol saccharides and Lipids in the Lungs of Experi. mental Animals, in 'Proc. Pneumoconiosis Confer ence (1959)', p. 442. London: J. \& A. Churchi⿺

HJERTQUist, S.-O. (1964a): Microchemical Analy:is of Glycosaminoglycans (Mucopolysaccharides) in Normal and Rachitic Epiphyseal Cartilage, Act $\mathrm{R}$. Soc. Med. upsalien, LXIX, 83.

- $(1964 b$ ): The Glycosaminoglycans (Mucopol文 saccharides) of the Epiphyseal Plates in Normal and Rachitic Dogs: Studies using a Colunf Procedure with Cetylpyridinlum Chloride, Acha Soc. Med. upsalien, LXIX, 83.

JACOBS, S., and MUIR, H. (1963): A Heparin Sul. phate-Peptide from Human Aorta, Biochem. $L$ 87, 38P.

JAKOWSKA, S. (1963): 'Mucous Secretions', Ann. N.Y. Acad. Sci., 106, 157.

JEANLOZ, R. W. (1960): The Nomenclature of Mf̊ce्? polysaccharides, Arth. Rheum., 3, 233.

-, (1963): Mucopolysaccharides (Acidic Glesce saminoglycans) in 'Comprehensive Biochemisfy ys 5, 262. Amsterdam and London: Elsevier.

KAPLAN, D., and MEYER, K. (1959): Ageing of Humai Cartilage, Nature. (Lond.), 183, 1267.

KELLY, J. W., BLOOM, G. D., and SCOTT, J. E. $(1963)^{\mathbb{D}}$ Quaternary Ammonium Compounds in Connective Tissue Histochemistry I. Selective Unblocking, 9 Histochem. Cytochem., 11, 791.

LACK, C. H., and RoGERS, H. J. (1958): Action Plasmin on Cartilage, Nature (Lond.), 182, 948.

LAURENT, T. C. (1964): Steric Interactions betweem Polysaccharides and Other Macromolecules: The Transport of Substances in Polysaccharide Media in Proc. N.A.T.O. Advanced Study Institute 'The Structure and Function of Connective and Skeletal Tissues, to be published.

LiNDAHL, U., and RoDEN, L. (1964): The Linkage of Heparin to Protein, Biochem. biophys. Re@ Commun., 17, 254.

LoEwI, G. (1961): The Acid Mucopolysaccharidef of Human Skin, Biochim. biophys. Acta. (Amst. 52, 435 .

saccharides of Human Skin, Biochim. biophy Acta. (Amst.), 27, 453.

MAlaWista, I., and SChUBERT, M. (1958): Chondrós mucoprotein: New Extraction Method ang Alkaline Degradation, J. biol. Chem., 230, 535.

MATHEWS, M. B. (1964): Structural Factors in Catio Binding to Anionic Polysaccharides of Connective Tissue, Arch. Biochem. Biophys., 104, 394.

MCClusKey, R. T., and THOMAS, L. (1958): The Removal of Cartilage Matrix. In Vivo by Papain Identification of Crystalline Papain Protease as th 8 Cause of the Phenomenon, J. exp. Med., 108, 37 
MeYer, K. (1960): In 'Molecular Biology', London: Academic Press.

-, Davidson, E. A., Linker, A., and Hoffman, P. (1956): The Acid Mucopolysaccharides of Connective Tissues, Biochim. biophys. Acta. (Amst.), 21, 506.

Montgomery, R., and Nag, S. (1963): Periodate Oxidation of Hyaluronic Acid, Biochim. biophys. Acta., (Amst.), 74, 300.

Muir, H. (1958): The Nature of the Link between Protein and Carbohydrate of a Chondroitin Sulphate Complex from Hyaline Cartilage, Biochem. J., 69, 195.

MUIR, H. (1964): Chemistry and Metabolism of Connective Tissue Glycosaminoglycans (Mucopolysaccharides) in 'International Review of Connective Tissue Research', 2, 101.

Partridge, S. M., and Davis, H. F. (1958): The Chemistry of Connective Tissues 4. The Presence of a Non-Collagenous Protein in Cartilage, Biochem. J., 68, 298.

- Davis, H. F., and Adair, G. S. (1961): The Chemistry of Connective Tissues 6 . The Constitution of the Chondroitin Sulphate-Protein Complex in Cartilage, Biochem. J., 79, 15.

, and ElsDEN, D. F. (1961): The Chemistry of Connective Tissues 7. Dissociation of the Chondroitin Sulphate-Protein Complex of Cartilage with Alkali, Biochem. J., 79, 26.

PIERCE, J. A. (1962): Age Related Change in the Fibrous Proteins of Lung, Arch. environm. Hlth., 6, 50.

Policard, A. (1962): The Conflict of Living Matter with the Mineral World: The Pneumoconioses, J. clin. Path., 15, 394.

Prodi, G. (1964): The Effect of Age on Acid Mucopolysaccharides in Rat Dermis, J. Gerentol., 19, 128.

Quintarelli, G., Scott, J. E., and Dellovo, M. C. (1964a): The Chemical and Histochemical Properties of Alcian Blue II. Dye Binding of Tissue Polyanions, Histochemie, 4, 86.

- (1964b): The Chemical and Histochemical Properties of Alcian Blue III. Chemical Blocking and Unblocking, Histochemie, 4, 99.

Roden, L., Gregory, J. D., and Laurent, T. C. (1964): Aminopolysaccharide Sulphate-Protein Complexes, Biochem. J., 91, 2P.

ROGERS, H. J. (1961): The Structure and Function of Hyaluronate in 'The Biochemistry of Mucopolysaccharides of Connective Tissues', p. 51, Cambridge: Cambridge University Press.

Saltzman, H. A., Schauble, M. K., and Siecker, H. O. (1961): Hexosamine Content of Aged and Chronically Diseased Lung, J. Lab. clin. Med., $58,115$.
- Siecker, H. O., and Green, J. (1963): Hexosamine and Hydroxyproline Content in Human Bronchial Cartilage from Aged and Diseased Lungs, J. Lab. clin. Med., 62, 78.

SAUNDERS, A. M. (1964): Histochemical Identification of Acid Mucopolysaccharides with Acridine Orange, J. Histochem. Cytochem., 12, 164.

SCHUBERT, M. (1964): Intercellular Macromolecules Containing Polysaccharides in, 'Connective Tissue: Intercellular Macromolecules', p. 119. Boston: Little, Brown.

ShATTON, J., and SCHUBERT, M. (1954): Isolation of a Mucoprotein from Cartilage, J. biol. Chem., 211, 565.

ShELDON, H., and Robinson, R. A. (1960): Studies on Cartilage II. Electron Microscope Observations on Rabbit Ear Cartilage following the Administration of Papain, J. biophys. biochem. Cytol., 8, 151.

SHETLAR, M. R., and MASTERS, Y. F. (1955): Effect of Age on Polysaccharide Composition of Cartilage, Proc. Soc. exp. Biol. Med., 90, 31.

SLUTSKII, L., and SHELEKETINA, I. (1959): Quantitative Determination of Collagen in Pulmonary Tissue, Vap. med. khimii., 5, 466.

STIDWORTHY, M. S., MASTERS, Y. F., and Shetlar, M. R. (1958): The Effect of Ageing on the Mucopolysaccharide Composition of Human Costal Cartilages Measured by Hexosamine and Uronic Acid Content, J. Gerontol., 13, 10.

SzIRMAI, J. (1963): Quantitative Approaches in the Histochemistry of Mucopolysaccharides, J. Histochem. Cytochem., 11, 24.

Thomas, L. (1956): Reversible Collapse of Rabbito Ears after Intravenous Papain and Prevention ofRecovery by Cortisone, J. exp. Med., 104, 245.

Tsaltas, T. (1958): Papain Induced Changes in Rabbit Cartilage. Alterations in the Chemical Structure of the Cartilage Matrix, J. exp. Med., 108, 507.

WAGNER, J. C., Munday, D. E., and HaRington, J. S. (1962): Histochemical Demonstration of Hyaluronic Acid in Pleural Mesotheliomas, J. Path. Bact. 84, 73.

Wood, G. C. (1960): The Formation of Fibrils from Collagen Solutions 3. Effect of Chondroitin Sulphate and Some Other Naturally Occuring Polyanions on the Rate of Formation, Biochem. J., 75, 605.

ZugiBe, F. I. (1962a): The Demonstration of Individual Acid Mucopolysaccharides in Human Aortas, Coronary Arteries and Cerebral Arteries I. The Methods, J. Histochem. Cytochem., 10, 441.

, $(1962 b)$ : The Demonstration of Individual Acid Mucopolysaccharides in Human Aortas, Coronary Arteries and Cerebral Arteries II. Identification and Significance with Ageing, J. Histochem. Cytochem., 10, 448. 